\title{
Egipto: Motivemos a los periodistas a cubrir tenmas de salud reproductiva
}

Frontiers in Reproductive Health

Follow this and additional works at: https://knowledgecommons.popcouncil.org/departments_sbsr-rh How does access to this work benefit you? Let us know!

\section{Recommended Citation}

"Egipto: Motivemos a los periodistas a cubrir tenmas de salud reproductiva," FRONTERAS Resúmenes de Investigación Operativa. Ciudad de México: Population Council, 2001. 


\section{Egipto \\ Diseminación}

\section{Resumen de IO 10 Después de asistir a una serie de reuniones informativas sobre salud reproductiva, un grupo de periodistas egipcios mejoraron su cobertura del tema. Las instituciones de salud pueden mejorar la cobertura de los temas de salud reproductiva si generan un flujo constante de información precisa a grupos amplios de periodistas.}

\section{Motivemos a los periodistas a cubrir temas de salud reproductiva}

\section{Antecedentes}

Para crear conciencia sobre cuestiones de salud reproductiva (SR) en el público en general, los proyectos FRONTIERS, del Population Council, y

POLICY, de Futures Group, organizaron conjuntamente varias conferencias de prensa y proporcionaron materiales de referencia a los principales reporteros de periódicos y revistas árabes. Entre mayo de 1999 y junio de 2000, el personal del proyecto trabajó estrechamente con 20 periodistas egipcios, incluyendo editores de artículos sobre mujeres y editores en jefe. Se realizaron cuatro conferencias de prensa, en las cuales se dio información sobre adolescentes, patrones maritales, tecnología anticonceptiva y menopausia. El paquete de prensa preparado para cada conferencia contenía hojas informativas, materiales de referencia, un directorio de expertos en los diferentes temas y una hoja de evaluación.

Para evaluar los reportajes sobre SR y monitorear la cobertura derivada de la intervención, los investigadores revisaron diariamente ocho importantes periódicos y nueve revistas árabes. Todos los artículos sobre SR se clasificaron de acuerdo al tema, extensión y uso de resultados de investigación.

\section{Resultados}

Las conferencias de prensa sí generaron cobertura. Una quinta parte de los 433 artículos de SR publicados en periódicos entre mayo de 1999 y marzo de 2000 cubrió temas discutidos en las conferencias de prensa. De igual manera, una tercera parte de los 127 artículos identificados en revistas cubrió cuestiones presentadas en dichas conferencias.

"Las cifras y los datos presentados tendrán mayor impacto en la opinión pública."

\section{-Periodista participante}

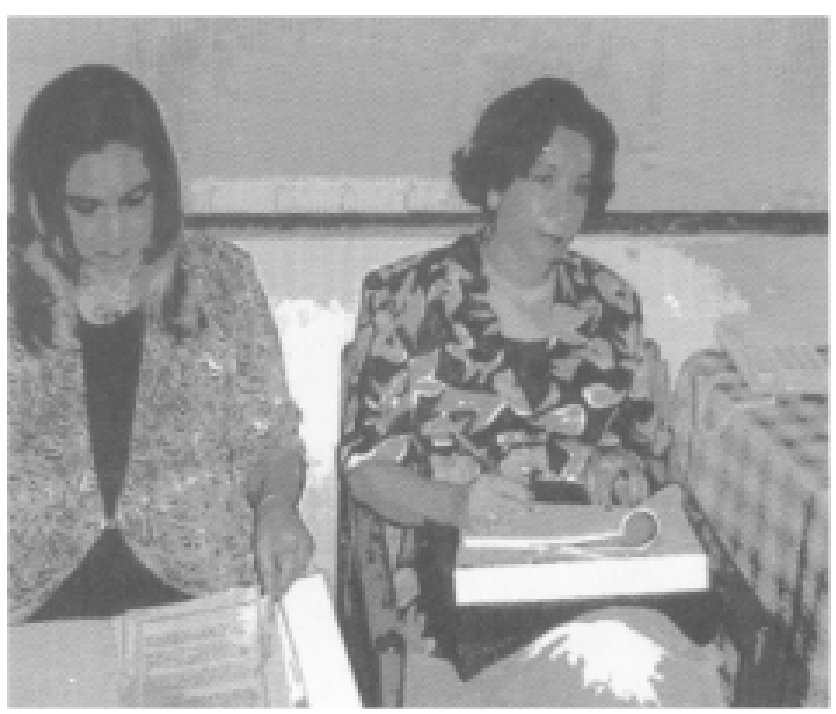


Los periodistas que asistieron a las conferencias de prensa informaron que sus conocimientos sobre SR habían mejorado y que pensaban usar los paquetes de prensa para escribir sus artículos. Algunos compartieron dichos paquetes con sus colegas.

El proyecto mejoró la calidad de los reportajes, aunque todavía es mucho lo que se puede mejorar. Aproximadamente uno de cada tres artículos que se basaba en la información divulgada durante las conferencias de prensa, mencionó resultados de investigación o datos del paquete de prensa. Aunque el personal del proyecto hizo hincapié en la necesidad de utilizar varias fuentes de información, la mayoría de los artículos se basaron sólo en una fuente.

Del total de páginas dedicadas a temas de SR, más de una de cada cuatro hablaba de la maternidad sin riesgos. El segundo tema más popular fueron las infecciones del tracto reproductivo, seguido de los de

\section{Temas de SR cubiertos en periódicos y revistas}

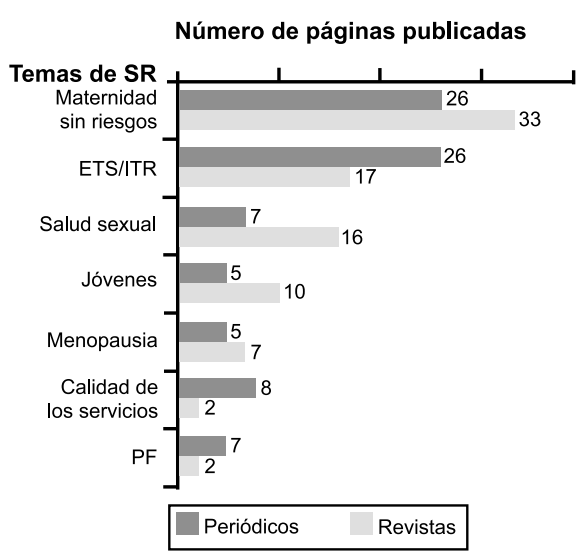

salud sexual, adolescentes, menopausia y calidad de los servicios (véase la Figura).

A la mayoría de los artículos sobre SR publicados en periódicos, se le dio un carácter noticioso, mientras que más de la mitad de los artículos publicados en revistas fueron reportajes especiales; la mitad de estos artículos fue de una página o más. Estos dos formatos de comunicación son útiles para la difusión de resultados de investigación: un gran número de tomadores de decisiones lee los periódicos, mientras que las revistas tienden a ser prestadas y a ser conservadas por mucho tiempo.

\section{Implicaciones normativas}

- La difusión de resultados de investigación debe incluir sesiones informativas y material para periodistas. Se deben establecer vínculos con reporteros de medios impresos y electrónicos.

Para ampliar la gama de los temas de SR que se presentan al público, se debería relacionar a más agencias locales con los medios. Sería conveniente proporcionar a los periodistas más información sobre planificación familiar y mutilación genital femenina*, ya que en la actualidad estos temas tienen poca cobertura.

Las instituciones de salud deben buscar el mejoramiento de la calidad de los reportajes generando un flujo constante de información precisa a los periodistas, y ayudarlos a identificar historias relevantes.

* Tema relevante en Egipto

Marzo 2001

Hegazi, Sahar and Mona Khalifa. 2000. Increasing the Coverage of Reproductive Health Issues in the Egyptian Press: Final Report. Para obtener más información o una copia del Informe Final en inglés de este estudio, escriba o llame a: Population Council, 6A Giza St.,P.O. Box 115, Dokki 12211, Giza, Cairo, Egypt. Tel.: 20-2-5725910; Fax: 20-2-5701804; E-mail: frontiers@pccairo.org

Este proyecto fue posible gracias al apoyo de la Agencia de los Estados Unidos para el Desarrollo Internacional (USAID) bajo el Acuerdo de Cooperación número y HRN-A-00-98-0012-00. 